very different degrees of antiquity and stages of evolution. It is therefore not only possible, but probable, that the Heidelberg and Neanderthal man are survivals of a very ancient type, and in no way indicative of the stage reached by Homo sapiens in the Pleistocene period. Using the same manner of reasoning, it is unlikely that the man of Java (Pithecanthropus), who is very little older in date than the Heidelberg man, and has a brain capacity of only about half that of modern man, represented the highest type of man of his time. He, too, was evidently a survival of an early stage. At least, it is difficult to believe that in a single and short geological period, even allowing that the extent of that period may be a million years, man could, even in that space of time, double his brain capacity. No parallel instance of so rapid a degree of evolution can be found in the history of Pleistocene mammals.

As regards the degree of relationship between man and the great anthropoids the opinion of scientific men has changed very little since Darwin's time. Huxley regarded the structural difference between man and the gorilla as about equal in degree to that which separated the gorilla from ordinary monkeys. The divergence between the gorilla and monkey is undoubtedly the greater. It can be safely said that the brain of the gorilla represents an intermediate stage between the brains of man and of the small anthropoid (the gibbon); the brain of the dog-like monkeys represents a still lower or more primitive stage. In 1904 Professor Nuttall confirmed the inferences which anatomists had drawn concerning the relationship of man to anthropoids and monkeys. He established the fact that the blood of the great anthropoids reacts to certain tests in almost exactly the same manner as human blood; the reaction becomes less in amount when the test is applied to the blood of monkeys. The response in the case of those of the old World is greater than with those of the New, thus bearing out the anatomists' opinion that the Old World monkeys are more recently related to the human stock than those of South America. There is also the evidence of disease. The great anthropoids are susceptible to syphilis-a human disease; monkeys can be inoculated with difficulty. Anthropoids in captivity are liable to typhoid fever, and when kept in captivity frequently die from that very human disease-appendicitis. There was no evidence that appendicitis occurred when the anthropoids lived in their native habitats and on their natural diet. Anthropoids are manifestly human as regards the nature of their diseases.

Although none of the existing anthropoids could be regarded as a human ancestor, there could be no doubt, seeing the extraordinary degree of structural similarity, that man and the great anthropoids were the products of a common stem. The gorilla shows the nearest structural approach to man. As to the time at which divergence occurred between the great anthropoid and human lines of descent no definite statement can as yet be made, but to obtain a working hypothesis it is necessary to place the point of divergence in a comparatively remote geological epoch-the Oligocene. The evolution of the great anthropoids from the small may have occurred early in the same period. The genealogical trees which have been constructed to explain the past history of the human stock are as yet little better than crude guesses to explain masses of ascertained facts of anatomy. Further discoveries. will certainly cause these genealogical trees to be modified in detail, yet the sequence of events in the evolution of man's body is becoming clear. The great mass of his brain and his nude skin were evidently the latest of human acquisitions; the adaptation of the lower limbs for walking and the modification of his teeth to their present form were earlier modifications of his structure. The size of his body and his stature were still older human features, while the chief structural modifications to adapt the body to an upright or vertical posture, were of very ancient origin.

A Correction.-Professor Keith asks us to apologize for an accidental slip of the pen, which prefixed the words "the late" to the mention of Mr. Barwell's name in a footnote to the first part of the report of the Hunterian Lectures on certain phases in the evolution of man (p. 737). Mr. Barwell's name stands second on the list of Fellows of the Royal College of Surgeons of Fngland. He became a Fellow in 1853 in the same year as Mr. Thomas Bryent, and two years after Professor P. Redfern, who in Whe is to know the his glad to know that Mr. Barwell, though retired from actual practice, is hale and well.

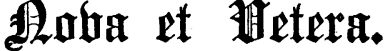

\section{THE GREGORIES.}

THERE is a French saying, $C e$ n'est pas lui qui a inventé la poudre, equivalent to our description of a man who will not set the Thames on fire. But there is powder and powder, and there is one which has made the name of its inventor in a sense immortal. This is Dr. James Gregory, whose name used to be a word of fear in nurseries owing to its association with the detested powder which he devised. A correspondent, who may possibly have suffered from a too liberal administration of the Pulv. Rhei Co., has asked for some particulars as to its inventor. James Gregory was a member of the famous family of Gregories which gave many men of high eminence in various spheres of activity to Great Britain. Their real name was MacGregor, but this was for a long time proscribed. It is curious to think that the professors of mathematics and medicine who played so large a part in the intellectual life of Aberdeen, Edinburgh, and other places during the eighteenth century and the beginning of the nineteenth should have been cousins closely related to Rob Roy, the famous freebooter. A short account of them is given by Miss Agnes Grainger Stewart in a little book entitled The Academic Gregories. ${ }^{1}$

James Gregorie, who was mediciner at Aberdeen University in the beginning of the eighteenth century, was the founder of the Aberdeen School of Medicine. It was his son that the freebooter offered to take with him and make a man of, an incident reproduced by Scott in the offer made by Baillie Nicol Jarvie to take his sons, which is related in Rob Roy. James Gregorie died in 1733.

He was succeeded by his son, James, who was professor at Aberdeen from 1732 to 1755 . He had a hot temper, and when he gave it free scope his friends would say, "Ah! this comes of not being educated by Rob Roy." Whether this tended to soothe his irritability we are not told. He left no children, but the name survived in John Gregory, who, after receiving his preliminary education at Aberdeen, went to Edinburgh in 1742 to study medicine. After three years he proceeded to Leyden, where among his companions was John Wilkes. King's College, Aberdeen, in his absence had obligingly sent him the degree of M.D., and on his return offered him the chair of philosophy, which he held from 1747 to 1749 . At the same time he engaged in general practice as a physician. In 1754 he resolved to seek his fortune in London ; in 1756, however, the death of his brother James having left the chair of medicine in Aberdeen vacant, he was appointed to it. But there were no students to teach, and the Aberdeen degree was a laughing stock, a state of things which chafed his proud spirit. His wife died in 1763, and in the following year he was invited to go to Edinburgh. There he was very successful in practice, and in 1766 he was appointed to the chair of the practice of physic, and was made first physician to the King for Scotland. He was the author of a Comparative View of the State and Faculties of Man with those of the Animal World, Lectures on the Duties and Qualifications of a Physician, Elements of the Practice of Physic, a textbook which he did not live to finish, and other works. He died suddenly in the middle of the session 1772-73, and the university authorities were at a loss how to arrange for the continuance of the lectures. His son James, the inventor of the powder, though only a student, offered to lecture till the end of the term, and extraordinary as it may seem, this proposal was gratefully accepted.

James Gregory was born at Aberdeen in 1753, and received his early education there. Afterwards he went to Oxford, but he cannot have remained long there, for he returned to Scotland and began his medical studies in 1767. After enlarging his experience at St. George's Hospital, London, he took his doctor's degree at Edinburgh in 1774, the subject of this thesis being De morbis coeli mutatione medendis. In it he adrocated the advantages of change of air in prolonging life, and dealt in detail with phthisis, hypochondriasis, and gout. He afterwards pursued his studies on the Continent, and in 1776 he was elected to the chair of the Institutes of

1 In the Famous Scots Series, published by Oliphant, Anderson, and Ferrier, Edinburgh and London, 1901. 